\title{
Uma análise de referências e significados associados às representações de animais presentes em rótulos de aguardente de meados do século $X X$
}

\author{
An analysis of references and meanings associated due animals representations \\ presented in cachaça labels from the mid-twentieth century
}

Swanne Souza Tavares de Almeida, Solange Galvão Coutinho

rótulos de aguardente, animais, análise semiológica, coleção almirante

\begin{abstract}
Este artigo apresenta uma análise semiológica de rótulos de aguardente que utilizam o animal como elemento pictórico principal. O estudo trata-se de um recorte da pesquisa realizada por Almeida (2018), que investigou a recorrência de animais nos rótulos de cachaça brasileiros, bem como as suas referências e possíveis significados relacionáveis. Os artefatos analisados fazem parte da Coleção Almirante (Fundaj, Recife-PE), composta majoritariamente por rótulos de cachaça entre as décadas de 1940 e 1950. A investigação do presente artigo se concentra na análise semiológica de espécimes utilizando como base o modelo de análise proposto por Penn (2002), aliado à taxonomia de Twyman (1979). A partir das apreciações, observa-se que enquanto signos da aguardente, os animais podem ser relacionados a vastas referências, incluindo elementos culturais, iconografia estrangeira, universo popular, o contexto açucareiro, conotações advindas de suas características biológicas e de comportamento, entre outras.
\end{abstract}

cachaça labels, animals, semiological analysis, almirante collection

This article presents a semiological analysis of cachaça labels that use the animal as the main pictorial element. The study is an excerpt from the research carried out by Almeida (2018), which investigated the recurrence of animals on Brazilian cachaça labels, as well as their references and possible related meanings. The analyzed artifacts are part of the Almirante Collection (Fundaj, Recife-PE), composed mostly of cachaça labels between the 1940s and 1950s. The investigation of this article focuses on the semiological analysis of specimens using the proposed analysis model of Penn (2002) as a basis, combined with Twyman's taxonomy (1979). From the appraisals, it is observed that as signs of cachaça, animals can be related to vast references, including cultural elements, foreign iconography, popular universe, the sugar context, connotations arising from their biological and behavioral characteristics, among others.

\section{Introdução}

Os animais aparecem como uma temática recorrente em impressos efêmeros brasileiros já no final do século XIX. Em visita feita ao Arquivo Nacional em 2012, observou-se representações de animais nos registros de marca deste período em imagens comerciais representantes de variados produtos tais como licor, sabão fumo e outros (fig. 1, fig 2). Águias, leões, gatos, elefantes, galos, peixes estão presentes nesses artefatos, demonstrando um espelhamento na

Anais do $10^{\circ} \mathrm{CIDI}$ e $10^{\circ} \mathrm{CONGIC}$

Kelli C.A.S. Smythe, Rafael de Castro Andrade (orgs.)

Sociedade Brasileira de Design da Informação - SBDI

Curitiba | Brasil | 2021
Proceedings of the $10^{\text {th }} \mathrm{CIDI}$ and $10^{\text {th }}$ CONGIC

Kelli C.A.S. Smythe, Rafael de Castro Andrade (orgs.)

Sociedade Brasileira de Design da Informação - SBDI Curitiba | Brazil | 2021 
iconografia estrangeira que era utilizada. Cardoso (2005), ao discorrer sobre produções deste período, corrobora com o argumento que as marcas registradas se formaram a partir de uma série de antecedentes tipográficos e imagéticos.

Figura 1 e Figura 2: Marca registrada com figura de galo e Rótulo M. Alves \& Cia - Rio de Janeiro. Fonte: Livros da Junta Comercial do Rio de Janeiro (1843). Acervo do Arquivo Nacional. Fotos: Swanne Almeida.
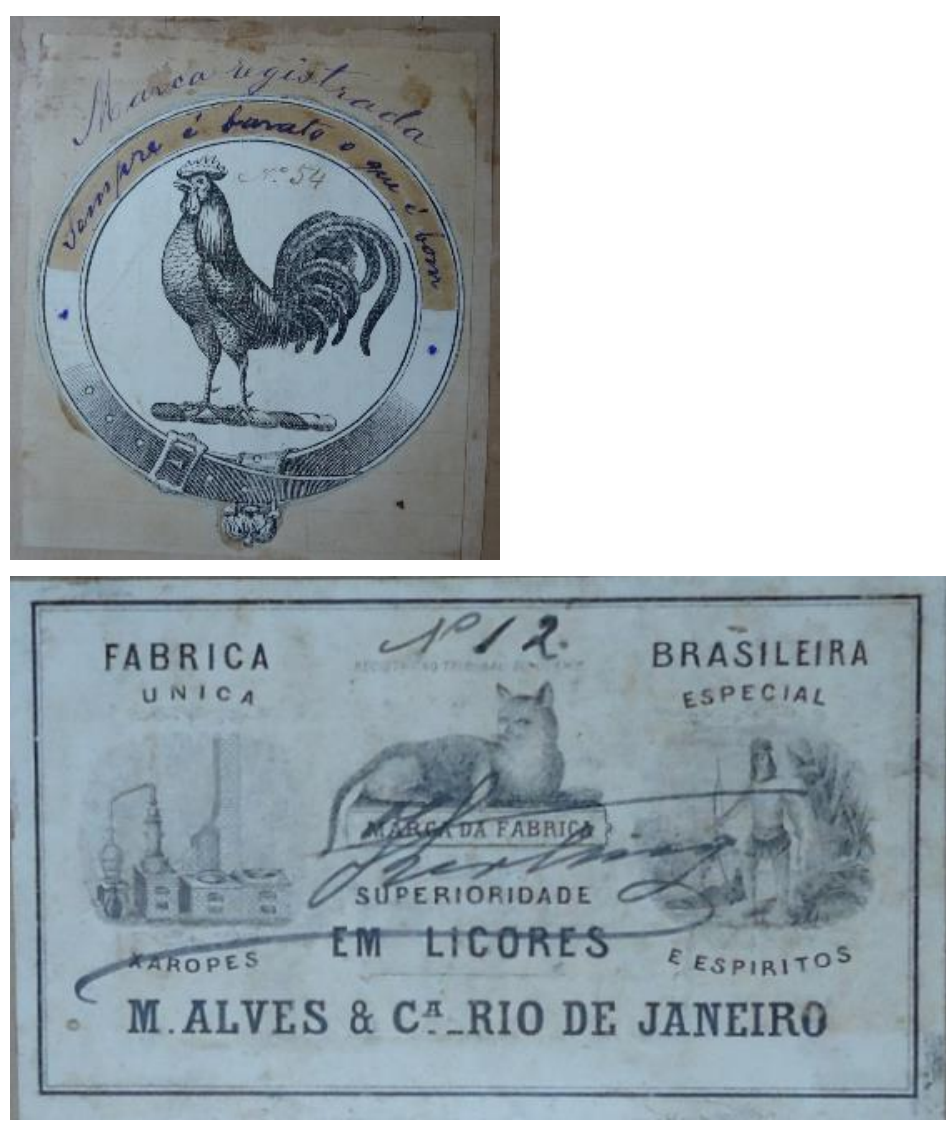

Avançando para o século XX e concentrando-se em rótulos de aguardente das décadas de 1940 e 1950 que utilizam o animal como temática principal, nota-se uma maior diversidade faunística nas representações. Além das espécies estrangeiras importadas (cavalo, boi, gato), destacam-se espécies nativas do Brasil (Almeida, 2018), como os chamados animais da terra de Freyre (2013): a onça, o tatu, o cágado, a raposa, a cobra.

A escolha desta temática como solução gráfica representante do produto "aguardente", foi objeto de estudo de Almeida (2018), que buscou desvendar os fatores que impulsionaram esta recorrência temática. A fim de demonstrar a confluência de referências e significados que permeiam a escolha desta temática no design destes artefatos históricos, este artigo apresenta um retrato da investigação realizada por Almeida (2018), focando-se na análise semiológica de alguns espécimes, a fim de apresentar as representações de animais enquanto signos da bebida aguardente. Os artefatos analisados neste estudo fazem parte da Coleção Almirante de rótulos de cachaça (Fundaj-PE), composta por rótulos de aguardente majoritariamente das décadas de 1940 e 1950 de temáticas variadas. 


\section{Construindo a análise semiológica}

Após estudo bibliográfico, o aporte teórico da semiologia, mostrou-se mais adequado para os objetivos e artefatos analisados. A semiologia permite a análise de sistemas de signos diversos, a exemplo de cardápios, embalagens, sinalização. Para análise, utilizou-se como base a proposta de Penn (2002), que aplica a semiologia na investigação de imagens publicitárias. Sendo os rótulos, imagens comerciais, pareceu pertinente a adoção deste caminho para conduzir a pesquisa por permitir o estudo dos significados atrelados às marcas de cachaça, bem como a análise de alguns elementos gráficos.

Para Penn (2002), o objetivo de uma análise semiológica é tornar explícito os conhecimentos culturais necessários para que o leitor compreenda a imagem. A autora descreve os seguintes estágios no processo de análise:

1. Escolha do material: Escolha das imagens que serão analisadas, de acordo com o objetivo do estudo e a disponibilidade do material.

2. Inventário denotativo: Identificação e reconhecimento dos elementos representados. A ideia desse estágio é fazer a catalogação do sentido literal do material (fig. 3).

Figura 3: Anúncio Givenchy e Inventário denotativo de anúncio. Fonte: Penn (2002).
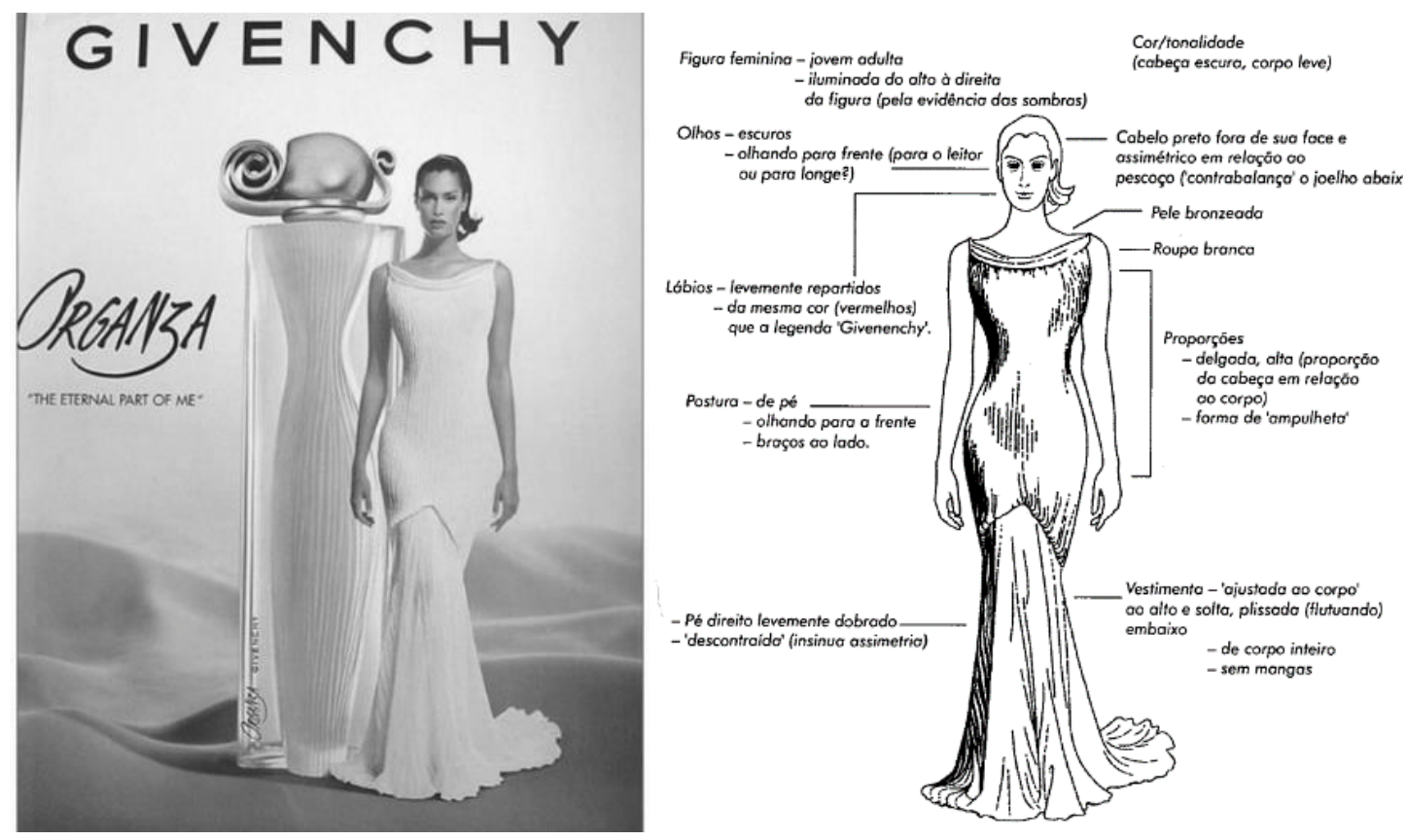

3. Níveis mais altos de significação: Análise dos aspectos conotativos. A partir do inventário denotativo, são feitas várias perguntas a cada elemento. Por exemplo: o que este elemento conota (possíveis associações imaginadas)? Como os elementos se relacionam? Quais conhecimentos culturais são necessários para o entendimento da mensagem? (Penn, 2002, p. 325). As escolhas dos elementos presentes na composição, bem como seus atributos sintáticos guiam a análise conotativa (fig. 4). 
4. Relatório: Seria a apresentação dos resultados, no modelo de preferência do pesquisador, seja por meio de tabelas ou da adoção de um enfoque mais discursivo, fazendo referência a cada nível de significação (denotação e conotação / mito), além dos conhecimentos culturais na leitura (fig. 5).

Figura 4: Sintagma e Paradigma aplicados aos elementos verbais do anúncio. Fonte: Penn (2002). Para Penn (2002), um paradigma é um grupo de termos que são semelhantes sob um aspecto e diferentes em outro. Por sua vez, o sintagma se refere a um conjunto de termos combinados entre si.

\begin{tabular}{|c|c|c|c|c|c|}
\hline & & & & $\leftarrow$ Sintagma $\rightarrow$ & \\
\hline & & Caixa & Orientação & $\begin{array}{c}\text { Proporção } \\
\text { da letra }\end{array}$ & Estilo do tipo \\
\hline$\uparrow$ & GIVENCHY & Caixa alta & Roman & Expandida & sanserif \\
\hline $\begin{array}{c}\text { Paradigmo } \\
\downarrow\end{array}$ & ORGANZA & $\begin{array}{c}\text { Caixa } \\
\text { alta/baixa }\end{array}$ & Itálico & Condensada & $\begin{array}{l}\text { manuscrita } \\
\text { a pincel }\end{array}$ \\
\hline & $\begin{array}{l}\text { ESCOLHAS } \\
\text { NÄO FEITAS }\end{array}$ & Caixa baixa & Blackslant & Regular & serif etc. \\
\hline
\end{tabular}

Figura 5: Exemplo de apresentação tabular dos achados. Fonte: Penn (2002).

\begin{tabular}{|c|c|c|c|}
\hline Denołação & Sintagma & Conotação/mito & $\begin{array}{l}\text { Conhecimento } \\
\text { cultural }\end{array}$ \\
\hline $\begin{array}{l}\text { Figura feminina: } \\
\text { postura, } \\
\text { vestes, efc. } \\
\text { Garrafa de } \\
\text { perfume: } \\
\text { proporçōes, } \\
\text { "estriamento", etc. }\end{array}$ & $\begin{array}{l}\text { Equivalência } \\
\text { sugerida pelas: } \\
\text { Proporçōes } \\
\text { assimétricas da } \\
\text { "ampulheta"; } \\
\text { tom, p.ex. "cabeça" } \\
\text { escura e "corpo" } \\
\text { "leve" } \\
\text { tamanho, localização; } \\
\text { adjacente, etc. }\end{array}$ & $\begin{array}{l}\text { Elegância clássica } \\
\text { Beleza perene (e } \\
\text { natural) }\end{array}$ & $\begin{array}{l}\text { Arquitetura grega: } \\
\text { da cariátide } \\
\text { colunas estriadas }\end{array}$ \\
\hline
\end{tabular}

\section{Percurso e adaptações do modelo de análise}

O processo de análise semiológica dos rótulos concentrou-se nas figuras dos animais e nas designações das aguardentes de cada exemplar. Para auxiliar na descrição do sintagma foi utilizada a taxonomia de Twyman (1979). O percurso da análise delineou-se em três etapas para obtenção dos resultados:

1. Seleção da amostragem: A seleção da amostragem para análise semiológica desenvolvida por Almeida (2018) levou em consideração o quantitativo de rótulos de animais por estado brasileiro e a maior diversidade possível de espécies para composição tendo analisado 35 espécimes. Neste artigo, por se tratar de um recorte, trazemos 6 desses exemplares; 
2. Aplicação de modelo de análise: Penn (2002) utiliza as denominações "imagem" e "texto" para diferenciar os elementos da "mensagem visual". No contexto deste estudo, aliamos a essa análise a taxonomia utilizada por Twyman (1979) (fig. 6), para diferenciar os elementos. $\mathrm{Na}$ análise foram incluídos os elementos pictóricos e o elemento verbal principal (Designação), para o inventário denotativo. Os elementos esquemáticos não foram analisados isoladamente, apenas quando associados ao verbal (designação) ou pictóricos (animal e demais elementos);

3. Coleta de dados complementar à análise: questionários, entrevistas em grupo (focus group) e entrevistas individuais: A fim de ampliar o repertório no processo de interpretação dos rótulos, foram realizados questionários em eventos na área de design, uma sessão de focus group com especialistas em design e história e entrevistas, sendo quatro delas com descendentes de proprietários de cachaças da época e uma com um ex-trabalhador da indústria gráfica recifense nos anos 70 .

Figura 6: Rótulo Carneirinho (PR) com indicações do elemento verbal principal (designação), esquemático (listel vermelho) e elementos pictóricos (animal e canas-de-açúcar).

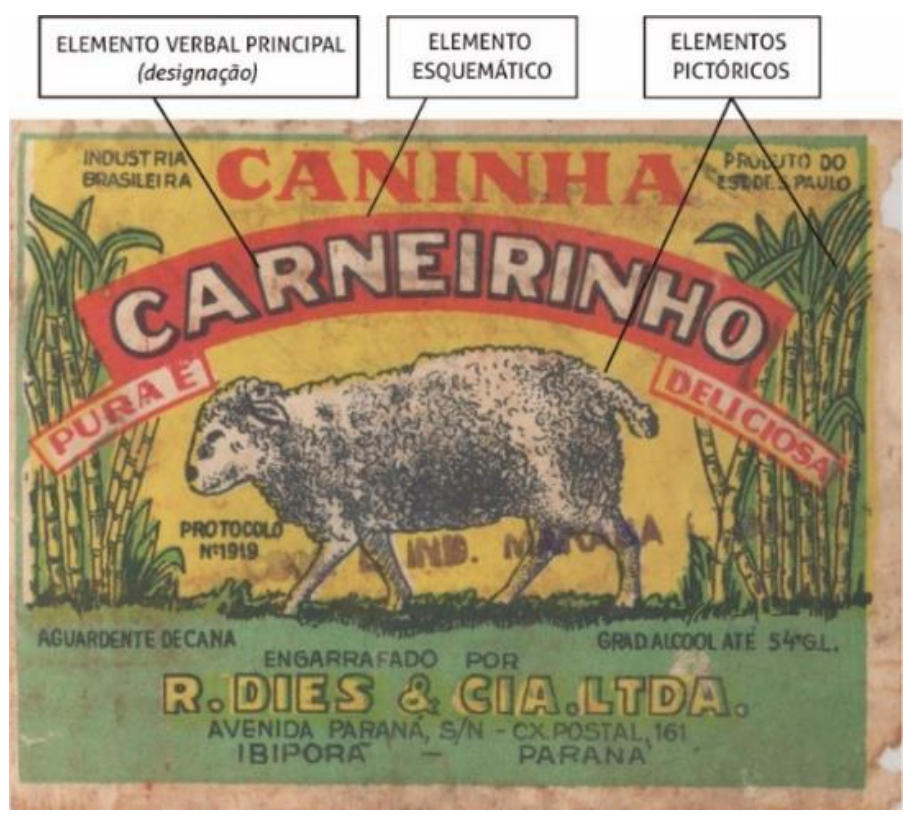

\section{Análise e discussão dos resultados}

A partir da aplicação do modelo de análise e das coletas de dados complementares realizadas, expõe-se nesta sessão dentro de um enfoque mais discursivo, os resultados das interpretações das produções. Os exemplares escolhidos contemplam referências que abarcam desde a vida rural ao jogo do bicho. Um mesmo exemplar apresenta diferentes referências e conotações. Cada rótulo exposto foi associado a uma expressão popular da época, reforçando as conotações associadas aos animais representados. 


\section{Salgar o galo}

De acordo com Mota (1978, p. 123), salgar o galo significa "ingerir, pela primeira vez no dia, qualquer bebida alcóolica". O galo é conhecido como símbolo de orgulho, reforçado pela sua forma de andar. Universalmente, esse animal é um símbolo solar, visto que anuncia a aurora (Chevalier \& Gheerbrant, 2018). O despertar e o cantar do galo são os conceitos mais adotados dentre as marcas de cachaça observadas que o escolheram como símbolo. Alvorada, Alvoradinha, Aurora, Canta galo são alguns dos nomes das aguardentes que trazem o "galo" ilustrando o rótulo. O despertar do galo pode ser associado ao vigor dado pela cachaça no início do dia. Em suas memórias, Gregório Bezerra relata como sua mãe o acordava de madrugada para cumprir uma de suas tarefas que consistia em juntar os bois e trazê-los de volta ao galpão:

— Acorde, meu fio. O galo já cantô três vêi!

Eu ficava dormindo. ela vinha, me levantava da esteira com toda a ternura. lavava-me o rosto e davame um gole de pinga, pois, segundo ela, servia para me dar-me coragem e espantar o frio.

Realmente, eu tomava o gole de pinga e o sangue invadia-me o rosto e as orelhas. (Bezerra, 2011, p.45).

Mota (1978) associa o galo à valentia, à voz ativa e o número 13 no jogo do bicho. Além desses significados, ou autor cita várias expressões, dentre as quais: galo arrastando a asa (cortejador de mulher), galo de briga (homem brigão), galo velho (indivíduo experiente) e cada galo em seu terreiro (cada pessoa em seu lugar). A figura do galo, com todo o seu simbolismo enredado tem uso recorrente há tempos, inclusive na heráldica, os fabricantes de aguardente fizeram uma escolha em cima de algo que já era muito presente no entorno e nas manifestações gráficas estrangeiras.

No rótulo Rabo de Galo (MG) (fig. 7), a conotação está mais próxima da vaidade do galo. A figura retratada é imponente e de domínio. O galo foi retratado de forma dinâmica com andar altivo. Conforme Souto Maior (1985), Rabo de galo é um tipo de coquetel, que mistura cachaça com vinho ou vermute, Mota (1978) aponta a expressão também como sinônimo de cachaça. 
Figura 7: Rótulo Rabo de Galo e detalhes da marca do produtor Antônio Rosa (AR) (estimado na década de 1950). Fonte: Coleção Almirante. Acervo da Fundação Joaquim Nabuco.

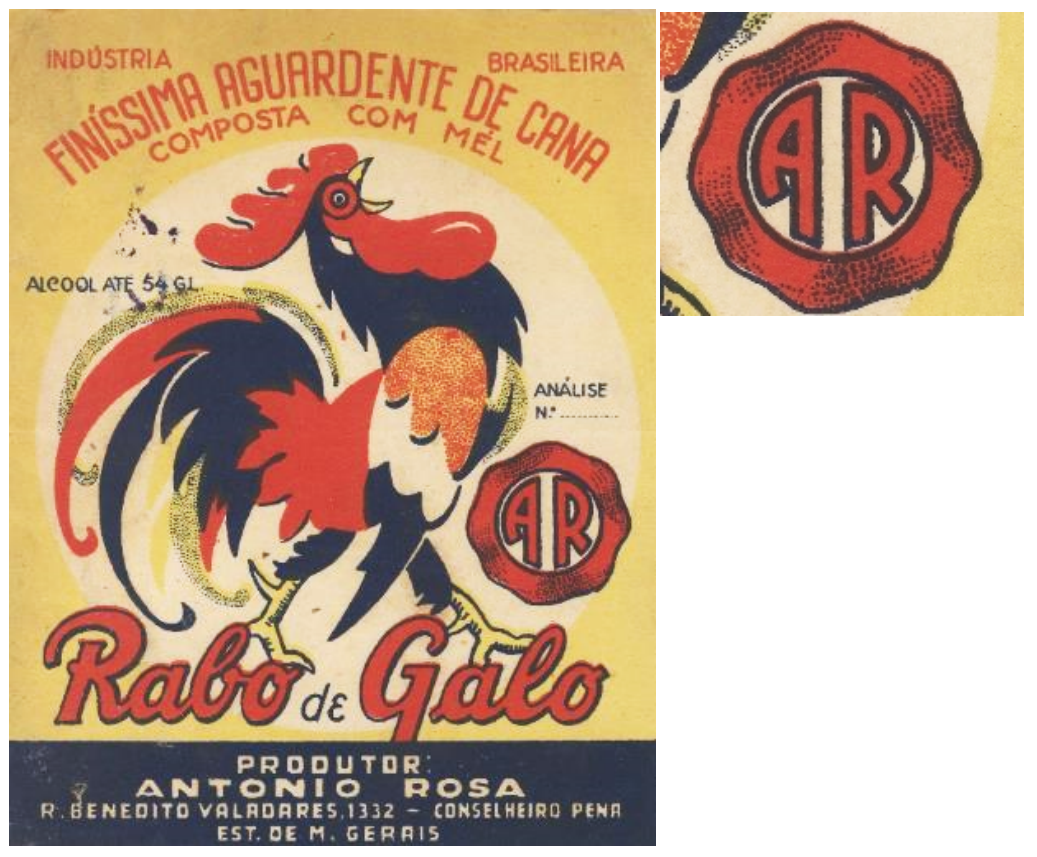

A sinuosidade da tipografia cursiva escolhida para designação entra em conjunto com o rabo do galo que também curvilíneo e pomposo. A grandiosidade desse animal pode ser associada à qualidade dessa aguardente. O enquadramento com a utilização de um círculo como elemento esquemático no plano de fundo, ressalta ainda mais o elemento pictórico. A representação não é naturalista, o colorido é muito mais para embelezar do que para detalhar as cores reais da plumagem de um galo realístico. Com apenas três cores e um trabalho de pontilhismo, foram alcançados outros tons, conferindo uma riqueza visual que reforça a superioridade da figura do galo.

\section{Por onde passa o boi passa o vaqueiro e o cavalo}

"Por onde passa o boi passa o vaqueiro e o cavalo" é um provérbio citado por Mota (1978, p. 75). Freyre (2013) cita que os dois grandes animais da civilização da cana-de-açúcar no Nordeste do Brasil foram o cavalo e o boi. Conforme o autor: "As ferraduras de cavalos e os chifres de boi - precisamente os dois animais mais ligados à civilização do açúcar, à conquista da mata pelo canavial - dão felicidade" (Freyre, 2013, p. 109). O cavalo está entre os bichos mais recorrentes na Coleção Almirante.

O cavalo foi importado para os engenhos do Nordeste. É um animal por excelência aristocrático, que conota domínio, superioridade e autoridade. Freyre (2013) nota que essa conotação de domínio da massa só se distancia nos cavalos dos gaúchos ou dos sertanejos. $O$ cavalo do senhor de engenho deveria ser majestoso, era tratado por ele como nenhum outro animal, com cuidados na sua higiene e alimentação.

$\mathrm{Na}$ primeira metade do século, o cavalo pode ser associado ainda ao jogo do bicho, correspondendo ao número 11 e ao divertimento das corridas. As primeiras diversões de turfe 
já ocorriam no Brasil no início do século XIX (Magalhães, 2005). O rótulo "Toni" (fig. 8) parece, à primeira vista, fazer referência a um cavalo de corrida. Conjectura-se duas possibilidades: a primeira que Toni seja um cavalo conhecido por participar de corridas da época ou algo do gênero; e a segunda, que seja um animal de propriedade do fabricante ou de alguém do seu conhecimento.

O cavalo do rótulo é majestoso, tem aparência de bem cuidado, forte e saudável. A ideia de que Toni retrate um cavalo campeão é reforçada pelo elemento pictórico da taça, cujo formato é semelhante a um troféu, como também pelo dinamismo de sua representação em plena corrida. A representação foi feita de forma naturalista com nuances de luz e sombra. O plano de fundo em preto colabora para o contraste da figura do animal. Toni tem uma expressão de determinação e foco, seu retrato como um cavalo de estirpe confere o status de qualidade à "cachaça superior" que representa. A tipografia escolhida para a designação Toni tem serifas triangulares suaves e foi sobreposta sobre o cavalo em posicionamento linear-curvilíneo, acompanhando o dinamismo do animal.

Figura 8: Rótulo Toni (estimado na década de 1950) e detalhes.

Fonte: Coleção Almirante. Acervo da Fundação Joaquim Nabuco.

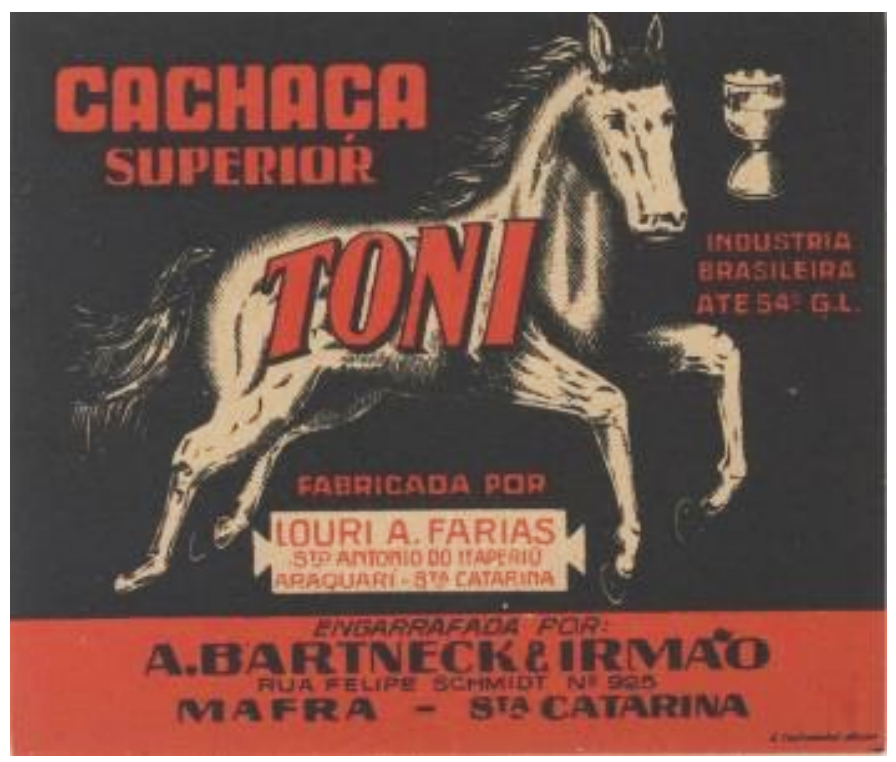

Encontra-se menções de um cavalo chamado Tony pelas décadas de 1920 e 1930. Tal cavalo pertencia a Tom Mix, um famoso ator norte-americano, sendo uma figura de sucesso que atuava especialmente em filmes de velho oeste. Esse ator teve vários cavalos, três dos quais se chamaram Tony, mas nas versões Tony II e Tony Jr (fig. 9). Salienta-se que Tony não era um cavalo branco, mas Tony II sim. É possível que a referência utilizada na verdade seja essa (Almeida, 2018). 
Figura 9: Nesta fotografia, Tom Mix está com seu cavalo Tony (domínio público).

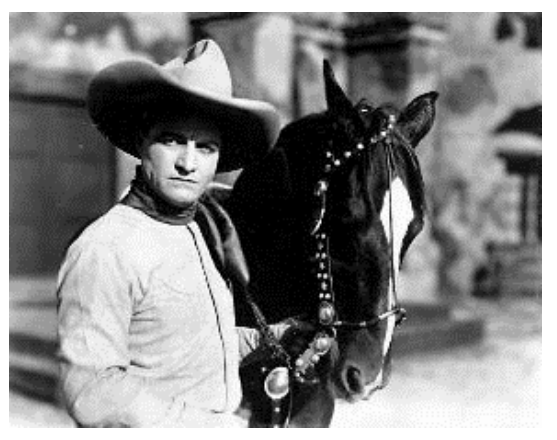

\section{Matar-o-bicho}

Matar-o-bicho é uma expressão que significa o mesmo que ingerir uma bebida alcóolica em jejum. Mata-bicho, por sua vez, é um eufemismo para cachaça (Souto Maior, 1985). "Matar bichos" por meio da caça configurava um dos lazeres do cotidiano rural do período. Há relatos em Freyre (2013) sobre caça às raposas, pacas, tatus, cutias, preás. Na coleção Almirante são encontrados exemplos de todos esses animais, incluindo ainda o mocó e a capivara.

Para ilustrar a referência a esta prática, expõe-se o exemplar de rótulo "Preá". Há relatos em Ihering (1940) sobre o gosto que se tinha pelas carnes dos roedores preá, paca e mocó. Apesar de ser menor que o mocó, a carne do preá tinha mais valor no mercado. O autor aponta que a predileção pelo preá ocorria mais no Nordeste e que era frequente ver o animal em feiras preparado como carne seca ao sol. No Ceará, preá pode significar o "indivíduo que toma parte nos divertimentos nada dispendendo dos mesmos" (Ihering, 1940, p. 652).

No grupo focal foi citado por um dos participantes: "Uma moça uma vez que trabalhava lá em casa falou: o pessoal passava o dia todinho tomando Pitú e assando preá". Nos versos expostos por Mota (1978), temos um retrato da vida "mansa" associada a esse animal, o que reforça o emprego dele como um signo do lazer, por meio da caça, de seu consumo enquanto aperitivo e do descanso associado ao ato de beber:

\footnotetext{
Minha gente venha vê

A vidinha do preá;

Morando nas macaxeiras,

Comendo sem trabalhar.

(Mota, 1978, p.172).
}

A apreciação pela carne do preá pode ser levada como significado para a bebida.

"Preá igual não há" é a frase grafada no rótulo pernambucano da aguardente Preá (fig. 10). Uma carne igual a do preá não há, e uma aguardente igual a "Preá" também não há. O rótulo "Preá" segue um modelo gráfico popular do período, o qual Almeida (2018) denomina de Modelo Pernambuco ${ }^{1}$,

\footnotetext{
${ }^{1}$ Almeida confere este título aos rótulos de cachaça de meados do século XX que utilizam em sua composição o preto no plano de fundo, normalmente o vermelho no elemento pictórico principal e o amarelo como terceira cor. Segundo a
} 
A tipografia utilizada neste exemplar é um tipo ornamental com serifas, sendo este um design específico recorrente em rótulos do período. O preá encontra-se sentado na parte superior do rotulo, como se apoiado na designação, de forma estática. A representação é naturalista, contudo, a cor se restringiu ao vermelho. Abaixo em campo amarelo, há uma cena de fábrica com o retrato de um engenho e o carregamento de cana em uma carroça. Este rótulo traz como outros apresentados, o selo com as iniciais do engarrafador.

Figura 10: Rótulo Preá (PE) e detalhes (estimado na década de 1940). Fonte: Coleção Almirante.
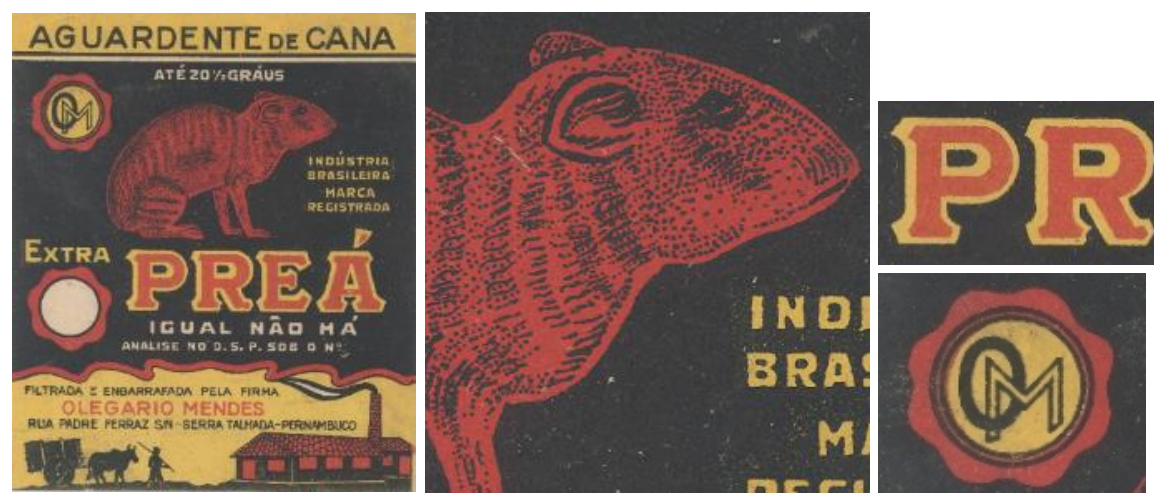

\section{Tira-gosto}

Ao falar sobre os peixes do mar e dos rios do Nordeste na civilização do açúcar, Freyre (2013) conta que o sucesso era o pescador trazer na jangada o cioba, a carapeba e a tainha ou carregar lagostas, lagostins e pitus. Assim como a caça, a pesca também era uma atividade de lazer no ambiente rural. O Rio Una, por exemplo, era famoso pelos seus pitus, o autor diz que nos engenhos da Várzea do Una tinha sempre pitus à mesa nos dias de grandes jantares. $O$ Rio Corrente da Bahia, por sua vez, teria ficado famoso pela presença do peixe dourado, outro muito apreciado pelo sabor. A culinária brasileira é repleta de frutos do mar até hoje: fritada de caranguejo, peixe cozido com pirão, sururu, peixe no coco, moqueca. Freyre (2013) aponta que tudo isso conectou de uma maneira muito íntima a mesa e a vida do povo nordestino às águas do rio e do mar.

Frutos do mar no litoral nordestino são muito presentes. Não é à toa que os rótulos da Coleção Almirante que trazem crustáceos como símbolos são todos dessa região. Já sobre os peixes, encontra-se incidências do animal até nos exemplares do sul do país. Salvo exceções como o tubarão e o cavalo marinho, a maior parte dos peixes que aparecem nos rótulos são voltados para o consumo. Os peixes presentes nos rótulos de aguardentes são aqueles que são apreciados à mesa como: surubim, dourado, garoupa, piraju, guajuba, piracanjuba. Notase a escolha dos peixes mais apreciados em sabor.

O tira-gosto, é quase sempre uma coisa salgada. Pode ser carne seca, camarão, batata frita, peixe. Como expõe Silva (1971, p. 194): "Serve para apurar o gosto da pinga, a semelhança dos fumantes com café". A aguardente "Surubim" traz em seu rótulo o peixe que intitula a bebida como o elemento pictórico principal. O surubim é um peixe que habita no sistema hidrográfico do Prata, Amazônico e do Rio São Francisco (Ihering, 1940). 
No rótulo "Surubim" (fig.11), o animal está sempre em algum tipo de ação não-naturalista, agarrado à garrafa ou mesmo a servindo. A garrafa possui um rótulo que corresponde ao da própria bebida, utilizando o recurso de metalinguagem. Na composição, são os bigodes do peixe que parecem ter sido fisgados pela aguardente. O surubim segue a ideia de tira-gosto, sendo um aperitivo de sabor apreciado, levando essa associação de carne "saborosa" à cachaça. A tipografia sem serifas de perfil quadrado, em disposição diagonal combina com o dinamismo presente nos elementos pictóricos.

Figura 11: Rótulo Surubim (SE) (estimado na década de 1950). Fonte: Coleção Almirante. Acervo da Fundação Joaquim Nabuco.

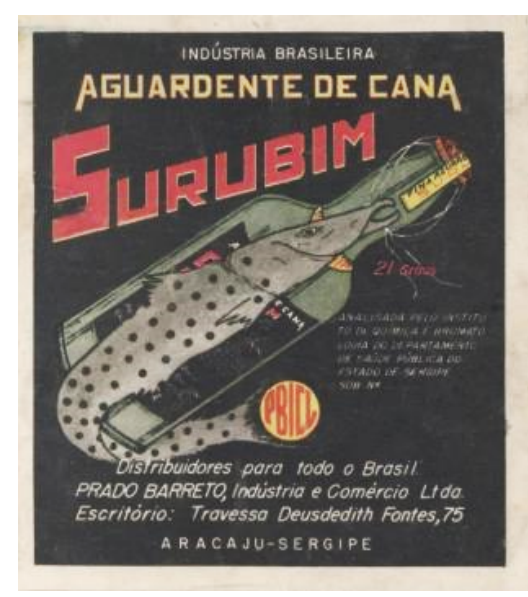

Na figura abaixo, apresenta-se o relato do que foi servido como almoço ao ex-rei belga Leopoldo III em sua visita à Brasília em 1962, entre as delícias estava o surubim, um peixe digno de um rei (fig. 12).

Figura 12: Relato da visita do ex-rei belga Leopoldo III à Brasília. Na descrição do almoço do ex-monarca foi servido o peixe surubim. Fonte: Última Hora (PR) (EX-REI, 1962). Acervo digital da Biblioteca Nacional.

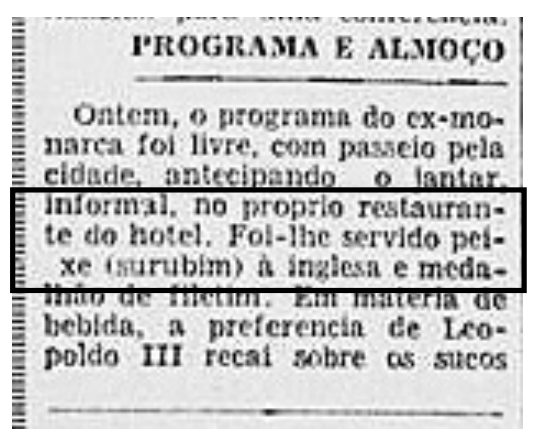

\section{Fazer uma fezinha}

Com sua história iniciada na cidade de São Sebastião do Rio de Janeiro em 1892, o jogo do bicho foi um divertimento que se popularizou muito rapidamente, agradando o público urbano e o rural. Para Magalhães (2005) os elementos intrínsecos ao bicho foram fundamentais para sedimentar o sucesso do jogo no mercado concorrido das loterias. $\mathrm{O}$ fato 
de a aposta ser vinculada a bichos no imaginário dos apostadores e não à frieza numérica, fazia com que o jogo se sobressaísse, posto que as características dos animais criadas pelos apostadores animavam as tentativas de apostas. Os animais do jogo são praticamente todos estrangeiros (fig. 13), apesar de muitos estarem incorporados nas criações brasileiras como o carneiro e a cabra.

Figura 13: Tabela do jogo do bicho. Fonte: Andrade, 2009.

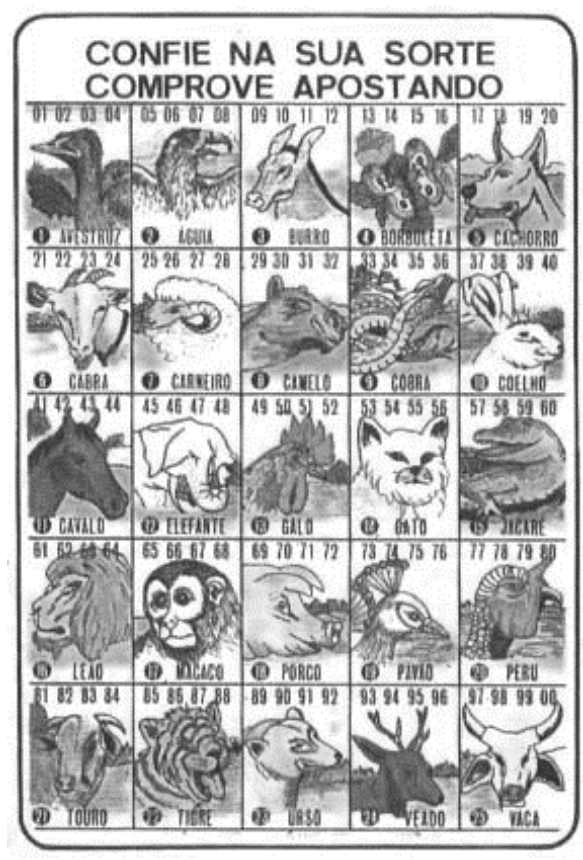

É de conhecimento comum que jogos de vício vêm facilmente acompanhados de bebida alcoólica. Nos rótulos da coleção Almirante, é possível encontrar todos os bichos que estão no jogo. O exemplo representante trazido aqui é o rótulo Pavão (BA). O Pavão é o número 19 no jogo de bicho e o foi o primeiro animal sorteado em sua história. Dentre os significados atribuídos a esse animal, estão o de uma pessoa vaidosa ou um sujeito que quer se destacar pelo vestuário (Mota, 1978). Há ainda as expressões: pé de pavão (ponto fraco de alguém), comeu carne de pavão (ficou orgulhoso por qualquer motivo), empavonado (orgulhoso), pavonear (exibir-se), ter penas de pavão (fazer figura às custas de alguém). O pavão é uma ave de estonteante beleza, sendo utilizada em propriedades rurais como uma ave ornamental.

O próprio rótulo destoa dos demais com todo seu decorativismo, exacerbado por referências do Art Deco e Art Noveau (Almeida, 2018). O pavão foi retratado de forma estático e naturalista, fortemente aliado a elementos esquemáticos. Os tipos da designação também são bem ornamentados com sombras e com uma decoração interna que dialoga com os detalhes nas penas do pavão. Apesar de o rótulo possuir vários elementos e ter um trabalho interessante na composição cromática, o pavão em si não foi tão bem detalhado, mas cabe destacar o bom trabalho feito na combinação das cores azul, amarelo e vermelho.

Conseguimos ver também o uso do preto e do azul claro em pequenos detalhes. A informação 
do fabricante parece ter sido impressa posteriormente, um indicativo de que se trate de um rótulo de estoque ${ }^{2}$ e portanto, o tenha sido utilizado por diferentes fabricantes.

Figuras 14: Rótulo Pavão (BA) e detalhes (década de 1940) Fonte: Coleção Almirante. Acervo da Fundação Joaquim Nabuco.

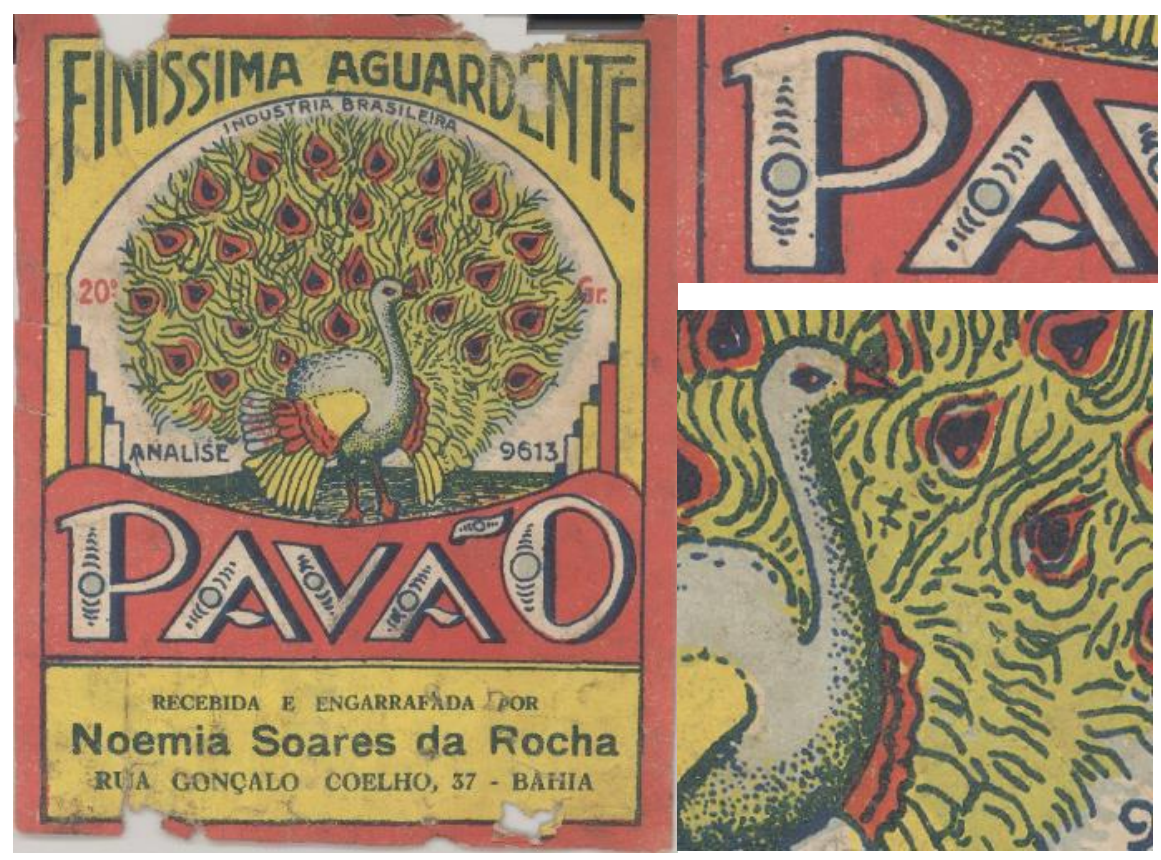

\section{Aquele cabra é muito águia}

O cabra que é muito águia é aquele que é sabido e tem muita experiência (Mota, 1978). As águias são os animais mais recorrentes na Coleção Almirante, juntamente com os galos, gatos e leões, estando presente em 26 dos 402 exemplares. A águia é um símbolo universal de poder, força e autoridade. Essa é uma ave guerreira e predadora, considerada como rainha das aves (Chevalier \& Gheerbrant, 2018). No Brasil, a águia é o número 2 no jogo do bicho e o símbolo da Academia de Força Aérea Brasileira. É certo que existem águias na fauna brasileira, mas as aves que aparecem na coleção não fazem relação pela designação da bebida com nenhuma águia específica, são todas denominadas genericamente de águias. A escolha recorrente deste animal parece ter mais influência estrangeira. Na Coleção Almirante, alguns desses exemplares trazem também águias em representações mais heráldicas, associadas a brasões.

O rótulo apresentado para análise que utiliza o animal águia é a Superfina Aguardente de Genipapo Alagoana (AL) (fig. 15). Esse exemplar causou grande discussão no grupo focal, devido à presença da marca registrada intitulada Pátria, que poderia indicar uma mensagem de cunho político. Nesse sentido, para alguns do grupo, a águia estaria simbolizando o patriotismo, nacionalismo. Ou ainda algo relativo ao militarismo ou a aeronáutica. Alguns

\footnotetext{
${ }^{2}$ Rótulos já impressos sem o título e fabricantes, os quais poderiam ser acrescentados posteriormente por outra impressão.
} 
associaram ainda que as cores azul e vermelho, bem como a águia poderiam estar simbolizando os Estados Unidos e as interações entre esse país e o Brasil durante a Segunda Guerra Mundial (Almeida, 2018). Observando as características do rótulo estima-se que sua datação seja do início da década de 1940, devido aos dizeres "isenta de saes de cobre", preocupação condizente dos produtores naquele período, como também o indicador telefônico de apenas 3 números (Almeida, 2013).

Figura 15: Rótulo Superfina Aguardente de Genipapo (década de 1940) e detalhes. Fonte: Coleção Almirante. Acervo da Fundação Joaquim Nabuco.

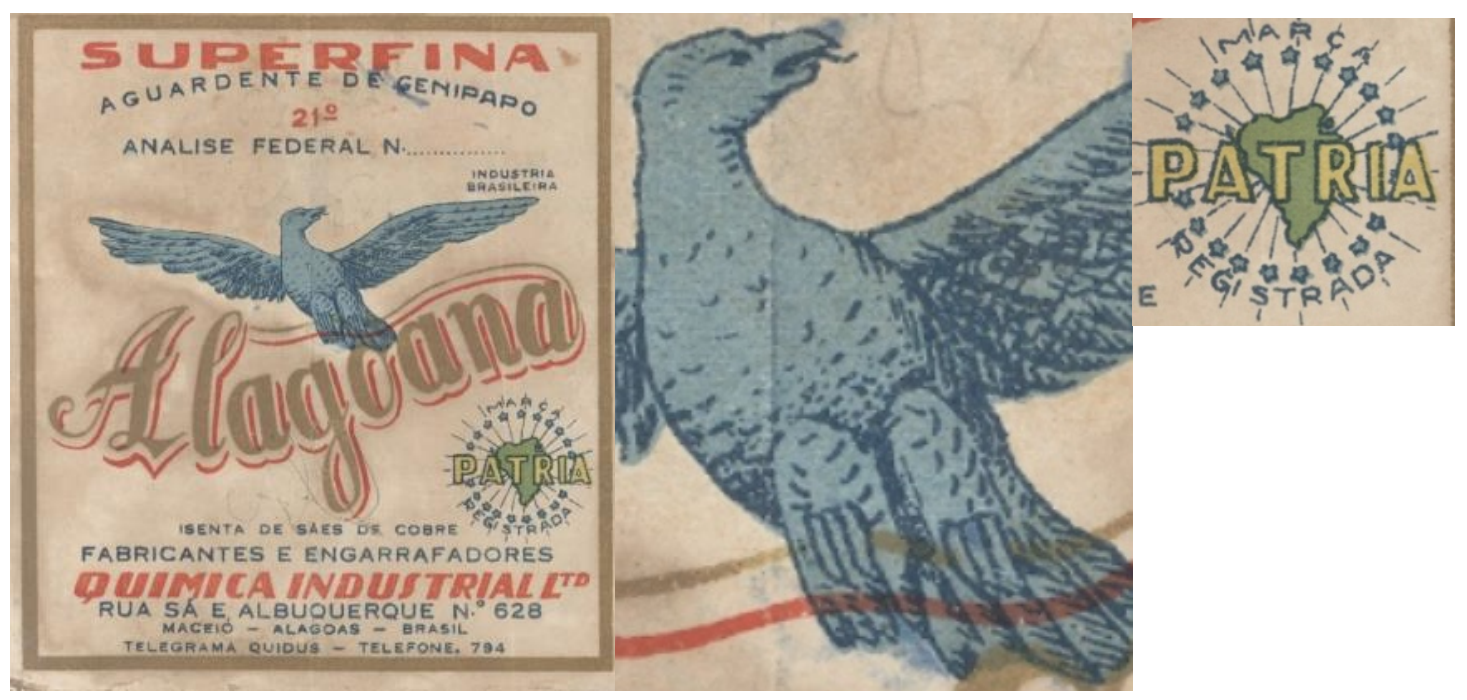

Acredita-se que a representação da águia neste rótulo confere um simbolismo para a superioridade nacional e o patriotismo. A designação "Alagoana" é uma referência à bebida que é produzida em Alagoas, numa valorização do produto da terra. A águia foi representada de forma dinâmica, sobrevoando a designação, contribuindo para a conotação da superioridade. A representação é naturalista, houve uma tentativa de detalhar as penas da ave, mas que careceu de técnica ou mesmo capricho do autor. A perspectiva da ave também está meio distorcida, possivelmente fruto de algum reaproveitamento de desenhos para composição do animal. Por outro lado, a qualificação "superfina" é contemplada por um letreiro caligráfico curvilíneo e bem desenhado, enobrecido também pelo uso da tinta dourada, algo não muito usual nos rótulos de aguardente. Nota-se o uso de cinco cores: dois tons de azul, vermelho, amarelo e dourado. No contexto dos rótulos de aguardente da época, isso é uma verdadeira extravagância, conferindo superioridade à produção gráfica.

\section{Considerações finais}

Enquanto signos da aguardente, os animais puderam ser relacionados com vastas referências, incluindo elementos culturais, iconografia estrangeira, universo popular, o contexto açucareiro, conotações advindas de suas características biológicas e de comportamento, entre outras. 
Nota-se também nos exemplares, associações às qualidades da bebida, a exemplo do termo "Finíssima" empregado no exemplar Pavão e "Superior" no rótulo Toni.

Pode-se dizer que a construção desses signos é feita pelos olhares do (1) proprietário da marca, (2) dos responsáveis pela confecção do rótulo na gráfica e (3) do público consumidor das marcas. Para o proprietário, a preocupação era escolher algo que vendesse bem. Suas referências partiriam do repertório do seu cotidiano e dos padrões gráficos e temáticos que vinham sendo utilizados por outras marcas.

O outro olhar na construção de significados era dos autores na casa de impressão. As casas litográficas tinham suas bibliotecas com desenhos e catálogos de referências. desenho seria construído a partir dos pedidos e referências trazidos pelo cliente e a das referências imagéticas aliadas à experiência do desenhista e dos demais técnicos gráficos. Esses técnicos seriam os definidores do sintagma, de como os elementos da linguagem gráfica se organizariam visualmente na construção da marca do produto.

$E$, por último, tinha-se o olhar do público, que interpretaria as imagens de acordo também com seu repertório e vivências e isto seria um dos fatores definitivos para marca se popularizar, visto que era importante que o público se identificasse com o bicho representado. A cachaça, enquanto produto "popular" desde cedo adquire a linguagem necessária para se identificar com seu público (Cunha Lima, 1998). Espera-se que esse recorte configure uma contribuição para o campo da memória gráfica ao apresentar as referências e significados associados ao uso de animais nos rótulos de aguardente do período citado, investigando como se constituíam estas soluções gráficas.

\section{Agradecimento}

Agradecimento especial à Fundação Joaquim Nabuco por ceder as imagens de rótulos da Coleção Almirante para este estudo.

\section{Referências}

Almeida, S. S. T. (2013). O sistema informacional de rótulos de cachaça brasileiros: o estudo comparativo entre os estados de Pernambuco, Rio de Janeiro e São Paulo. 2013.

Dissertação (Mestrado em Design) - Centro de Artes \& Comunicação, Universidade Federal de Pernambuco, Recife.

Almeida, S. (2018). Bichos Boêmios: um estudo sobre recorrências, referências e análise de significado dos animais nos rótulos de aguardente da Coleção Almirante. Tese (Doutorado). Recife: Universidade Federal de Pernambuco.

Bezerra, G. Memórias. São Paulo: Boitempo, 2011. Disponível em: https://books.google.com.br/books?id=eHF1z5tvkB0C\&printsec=frontcover\&hl=pt-

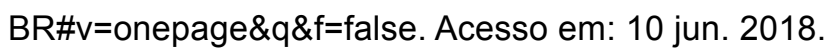

Cardoso, R. (org.). (2005). O design brasileiro antes do design: aspectos da história gráfica, 1870-1960. São Paulo: Cosac Naify.

Chevalier, J.; Gheerbrant, A. (2018). Dicionário de los símbolos. Edição Digital: Epublibre. 
Coleção Almirante: Rótulos de cachaça. [S. I.], [194-?-195-?]. Acervo da Fundação Joaquim Nabuco. 4.743 rótulos.

Cunha lima, E. L. (1998). Cinco décadas de litografia comercial no Recife: Por uma história das marcas de cigarro registradas em Pernambuco. 1998. Dissertação (Mestrado em Design) Departamento de Artes \& Design, Pontifícia Universidade Católica do Rio de Janeiro, Rio de Janeiro, 1998.

Ex-rei belga hoje com TN em Brasília. (1962). Última hora, Paraná, p.6, 20 fev. Disponível em<http://memoria.bn.br/DocReader/docreader.aspx?bib=830348\&pesq=surubim>. Acesso em 10 fev. 2018.

Fonseca, B. (1950). Coluna do fã. A cena muda, n. 8, p.23, 21. fev.

Freyre, G. (2013). Nordeste: aspectos da influência da cana sobre a vida e a paisagem do Nordeste do Brasil. 1 ed. Digital. São Paulo: Global Editora.

Ihering, R. V. (1940). Dicionário dos animais do Brasil. São Paulo, [s. n.],

Magalhães, F. S. (2005). Ganhou leva... Do vale o impresso ao vale o escrito. Uma história social do jogo do bicho no Rio de Janeiro. Tese (Doutorado em História Social) Universidade Federal do Rio de Janeiro, Rio de Janeiro.

Mota, M. (1978). Os bichos na fala da gente. 2 ed. Rio de janeiro: Tempo brasileiro; Brasília: INL.

Penn, G. (2002). Análise Semiótica de Imagens Paradas. In: BAUER, M. W.; GASKELL, G. Pesquisa qualitativa com texto, imagem e som: um manual prático. Petrópolis: Vozes, p.319-342.

Silva, V. A. da. (1971). A cachaça e sua contribuição folclórica. Brasil Açucareiro, n. 2, p.194, ago.

Souto maior, M. (1985) Dicionário folclórico da cachaça. 3 ed. Recife: Fundaj, Editora Massangana.

Twyman, M. L. (1970). A schema for the study of graphic language. In: Paul A. Kolers, Merald E. Wrolstad \& Herman Bouma (org.). Processing of visible language. Nova York \& Londres: Plenum Press, v. 1, p. 117-150.

\section{Sobre as autoras}

Swanne Souza T. de Almeida, Doutora, IFPE, Brazil <swanne.almeida@olinda.ifpe.edu.br> Solange Galvão Coutinho, PhD, UFPE, Brazil <sol2015ufpe@gmail.com> 